(Archer et al., 1965). By comparison our figure of $37 \%$ is surprisingly high, and as examination of a single specimen must be regarded only as putting a lower limit on the number infested, a more thorough search would doubtless have yielded more positives.

The various regions covered by our survey contributed roughly equal numbers of boys and girls with the single exception of Pakistan, where boys outnumbered girls by five to one. This exception presumably has a sociological basis which may extend to the finding of a greater hookworm carriage rate in boys, whereas the girls of this population have higher carriage rates for both hymenolepis and ascaris. The Pakistani girls and boys thus behave as distinct populations; perhaps the activities of the boys make them more liable to acquire hookworm and the activities of the girls make them prone to acquire hymenolepis and ascaris. We have not determined the reason for these differences.

The regional differences in the carriage patterns have already been considered but the low carriage rate in the African group (Kenya 16\% and Uganda 7\%) contrasts with the high rate in the West Indian group $(51 \%)$ and South-east Asian groups (30$40 \%$ ). The dominance of trichuris infestations and the absence of hymenolepis are notable in those from Hong Kong and the West Indies.

Our figures clearly indicate the need to examine the faeces of all newly arrived immigrant children, using a concentration method when possible. While many infestations are probably light and will disappear in time, they nevertheless require recognition because the carrier may suffer disease. The possibility of medical and surgical manifestations of infestation must be constantly in mind when dealing with these children. Secondly, as has been pointed out by Buckley and Pester (1965) and by Archer et al. (1965), there is a risk of transmission of helminths in this country, and the large number of children infested constitute a substantial reservoir. These authors give five instances where transmission has taken place to children who have never been abroad-three cases of hookworm, one case of hymenolepis, and one case of ascaris-and it must be assumed that other unrecognized instances exist.

The risks of transmission are largely unknown and depend on variable climatic conditions as well as on social circumstance. The hookworm requires warm, humid conditions-a hot wet summer-to develop in earth to the larval infective stage which then penetrates the skin. Eggs of ascaris and trichuris require only a period for embryonation before becoming infective. Hymenolepis ova require only transmission to the mouth for infection. In a recent study in Prague (Kawaciuková, 1971) eggs of Enterobius vermicularis were found in modern heated swimming pools; the author also stated that the ova of ascaris, trichuris, and hookworm will mature despite a chlorination level of $0 \cdot 2-0.3 \mathrm{mg} /$ litre-that is, $0 \cdot 2-0.3$ p.p.m.-residual chlorine, which is adequate for bacteriological purposes. We have incidentally observed that these eggs will continue to embryonate even in $10 \%$ formalin in the laboratory. Thus it cannot be assumed that disinfectants used against bacteria will necessarily be effective against helminth ova.

Finally, the difficulty of ensuring effective treatment of these children is a real one. Many have not got doctors of their own; there are often substantial language barriers which make intelligible instructions hard to give and effective eradication of worms hard to ensure. Early in the survey we referred positives to a hospital so that we could be certain that they got treatment and with the correct anthelmintics, but we do not know whether the medications prescribed were actually taken and it has not proved practicable to follow the children up to find out whether the treatment was effective.

We are much indebted to Dr. E. L. M. Millar, M.O.H. of Birmingham, for his continuing support and interest. Thanks are also due to the staff of the School Health Service and Public Health Laboratory for their co-operation. In particular we must mention the nurses at Canterbury House School Clinic and the education welfare officers, without whose perseverance many of the specimens would not have been obtained.

\section{References}

Anderson, E. S. (1971). The Times, 31 December 1971. Archer, D. M., Bamford, F. N., and Lees, E. (1965). British Medical

Barua, D. (1969). Quoted in Lancet, 2, 195.

Bart, K. J., and Mosley, W. H. (1970). Lancet, 2, 47.

British Medical fournal, 1971, 4, 507.

Buckley, J. J. C., and Pester, F. R. N. (1965). British Medical fournal, 2, 106. Carpenter, K. P. (1966). Monthly Bulletin of the Ministry of Health and the Public Health Laboratory Service, 25, 58.

Hsieh, H. C. (1963). World Health Organization. Technical Report Series, No. 255, Annex 3.

Kawaciuková, J. (1971). Československá Epidemiologie, Mikrobiologie, Immunologie, 20, 156.

P.H.L.S. Report (1959). Monthly Bulletin of the Ministry of Health and the Public Health Laboratory Service, 18, 86.

Sasa, M., Hayashi, S., Tanaka, H., and Shirasaka, R. (1958). Japanese Journal of Experimental Medicine, 28, 129.

Sen, R., Sen, D. K., Chakrabarty, A. N., and Ghosh, A. (1968). Lancet, 2,

The Times, 17 November 1971.

Thompson, R. G. (1972). Fournal of Clinical Pathology. In press.

Turner, W. (1970). Quoted in Medical Officer, 124, 90 .

W.H.O. Report (1964). World Health Organization. Technical Report Series, No. 277 .

Woodruff, A. W. (1968). Transactions of the Royal Society of Tropical Medicine and Hygiene, 62, 446.

\title{
Aerosol Hazards from Some Clinical Laboratory Apparatus
}

\author{
D. A. RUTTER, C. G. T. EVANS
}

British Medical fournal, 1972, 1, 594-597

\section{Summary}

Infectious diseases, such as infectious hepatitis, may be transmitted from patients to staff in clinical laboratories and dialysis units during the performance of necessary procedures. This prompted us to examine the propensity of several items of commonly used apparatus to produce aerosols of infected blood. These were a microhaematocrit

Microbiological Research Establishment, Porton, Salisbury, Wiltshire

D. A. RUTTER, M.B., B.CHIR., Senior Scientific Officer

C. G. T. EVANS, M.SC., M.I.BIOL., Principal Scientific Officer meter. We also compared some blood sample tubes with two types of lid. The results showed that all of these are potential sources of infection for laboratory staff.

\section{Introduction}

"It may be stated without fear of contradiction that every infectious microbiological agent which has been studied in the laboratory has, at one time or another, caused infection of operators" (Chatigny and Clinger, 1969). The recent epidemics of infectious hepatitis in several British hospitals, with fatal sequelae, have underlined yet again the readiness with which 
hospital staff may acquire serious infections from patients. However, such epidemics are only the more conspicuous manifestations of the ever present problem of laboratory-acquired infection. Although precise statistics are not available their frequency seems to have increased at a rate nearly parallelling the increases in clinical laboratory work (Chatigny, 1961); in one laboratory the work load doubled between 1967 and 1970 (Griffiths, 1971). More recently, greater awareness of the problem and a slowly diminishing reluctance to report cases may have helped to maintain the laboratory infection rate. Although the alarming number of road accidents is everywhere acknowledged, it is not generally realized that their mortality rate of $2.7 \%$ is less than the 5\% reported for laboratory infections (Sulkin, 1960). The deaths of 4 out of the 12 staff infected in the recent Edinburgh epidemic of infectious hepatitis (mentioned by Hawe, Goldsmith, and Jones, 1971) underline the danger of acquiring infectious diseases in laboratories or dialysis units.

All available information indicates that about $80 \%$ of laboratory infections are the result of no overt "accident" but probably follow inhalation of aerosols of infectious particles liberated by normal laboratory techniques (Chatigny, 1961); bacteriological technique has evolved to protect cultures, not workers. The operations most prone to cause laboratory-acquired infection (those producing aerosols containing $1-5-\mu \mathrm{m}$ particles) are well documented and have been reviewed frequently-see, for example, Darlow (1969). Those most likely to be encountered in a clinical laboratory are shown in Table $I$.

TABLE I-Hazardous Operations in the Clinical Laboratory

\begin{tabular}{|c|c|c|}
\hline Manoeuvre & Aerosol Generated by & Other Risks \\
\hline Mixing or shaking & $\begin{array}{l}\text { Forcing blood through needle } \\
\text { and needle off syringe } \\
\text { Squirting blood into container } \\
\text { Vibrating needle } \\
\text { Inevitably produce stable }\end{array}$ & $\begin{array}{l}\text { Spray to eyes and } \\
\text { mucous membranes } \\
\text { Skin contamination, } \\
\text { bloody fingers wiped } \\
\text { on white coat etc. } \\
\text { Self-inoculation } \\
\text { Splashing }\end{array}$ \\
\hline Transport to laboratory & $\begin{array}{l}\text { Aerosol produced in air-space } \\
\text { of tube by shaking is released } \\
\text { on opening tube }\end{array}$ & Leaky tubes and caps \\
\hline Opening containers & $\begin{array}{l}\text { An ever-present and inevitable } \\
\text { danger }\end{array}$ & Skin contamination \\
\hline Centrifugation & $\begin{array}{l}\text { Tubes leaking or breaking. } \\
\text { Aerosol in air-space released } \\
\text { on opening tubes }\end{array}$ & $\begin{array}{l}\text { Machine } \\
\text { contaminated }\end{array}$ \\
\hline Pipetting & $\begin{array}{l}\text { Blowing out last drop. Dropping } \\
\text { blood or plasma on to bench or } \\
\text { plates, etc. }\end{array}$ & $\begin{array}{l}\text { Ingestion; but mouth } \\
\text { pipetting should } \\
\text { never occur }\end{array}$ \\
\hline Bacterial loops & $\begin{array}{l}\text { Hot loops sizzle; vibrating loop; } \\
\text { plate spreading; flaming loop }\end{array}$ & \\
\hline Disposal and washur & Almost all activities & $\begin{array}{l}\text { Usually the } \\
\text { responsibility of } \\
\text { least trained staff } \\
\text { May not be safe } \\
\text { (Line, 1972). } \\
\text { Require intelligent } \\
\text { use, maintenance, } \\
\text { and testing }\end{array}$ \\
\hline
\end{tabular}

We have examined several items of apparatus commonly present in clinical laboratories which did not seem to have been investigated previously and which we considered especially likely to generate aerosols. These were: a microhaematocrit centrifuge, an AutoAnalyzer sample stirrer, and a blood tonometer. In the course of these investigations we also examined the effects of opening blood sample tubes of types used in clinical laboratories.

\section{Materials and Methods}

The blood used in all our experiments was heparinized human or rabbit blood mixed with a concentrated suspension of a tracer organism, Serratia marcescens, to give a final concentration of about $10^{\circ}$ viable particles per $\mathrm{ml}$.

Airborne particles were collected with a Bourdillon slit sampler (Cassella, London) with a sampling rate of 1 cubic foot $\left(0.028 \mathrm{~m}^{3}\right)$ of air per minute impinging on to tryptic soy agar (Oxoid) plates. These were incubated for 24 hours at $30^{\circ} \mathrm{C}$ and then left on the bench for $\mathbf{4 8}$ hours. This allowed the characteristic pigment to develop which enabled the $S$. marcescens colonies to be readily distinguished from any room contaminants. Room samples were taken before and after each experiment as controls.

Tests were done on blood sample tubes either a quarter full $(2.5 \mathrm{ml})$ or filled to $1 \mathrm{~cm}$ from the top $(10 \mathrm{ml})$.

The experiments were conducted in a laboratory ventilated with filtered air at about five air changes per hour.

\section{Results}

\section{MICROHAEMATOCRIT CENTRIFUGE}

"One large problem experienced in haematology [is] that associated with breakage in the microhaematocrit centrifuge" (McLellan and Canning, 1971); when this occurs blood, forced through the slit formed by the cover and the rim, emerges as a fine spray athigh speed, and whilesome impinges on thelid the rest is carried away in the airflow through the machine (see below). In principle this is very similar to devices used for the deliberate generation of aerosols. The blood stains inside the lid of many hospital machines visibly reflect the hazard inherent in the use of this centrifuge. In the instrument up to 24 capillary tubes, each containing about $50 \mu \mathrm{l}$ of blood and retained by a tightfitting cover, are rotated at more than 12,000 r.p.m. In the model tested by us the rotor induced a negative pressure under the lid of $145 \mathrm{~mm}$ of water and streams of air which emerged through two rear outlets (not present in earlier models) at 760 and 890 linear feet (232 and $271 \mathrm{~m}$ ) per minute respectively.

Haematocrit tubes were filled by holding them horizontally and touching one end with the blood sample; external contamination of the tubes was thus minimized; nevertheless samples taken in the air stream 3 feet $(0.9 \mathrm{~m})$ from the machine during centrifugation contained the tracer organism. Even with extreme precautions, such as carefully wiping all blood off the outsides of the tubes before centrifuging them, the tracer was still detected. No aerosol was detected as the capillaries were filled. Fig. 1 shows the results of five-minute air samples taken at nose height ( $5 \mathrm{ft} 6 \mathrm{in} ; 1.68 \mathrm{~m}$ ) before, during, and after spinning blood samples when three tubes leaked. The first sample (A) was taken while the centrifuge tubes were being prepared and

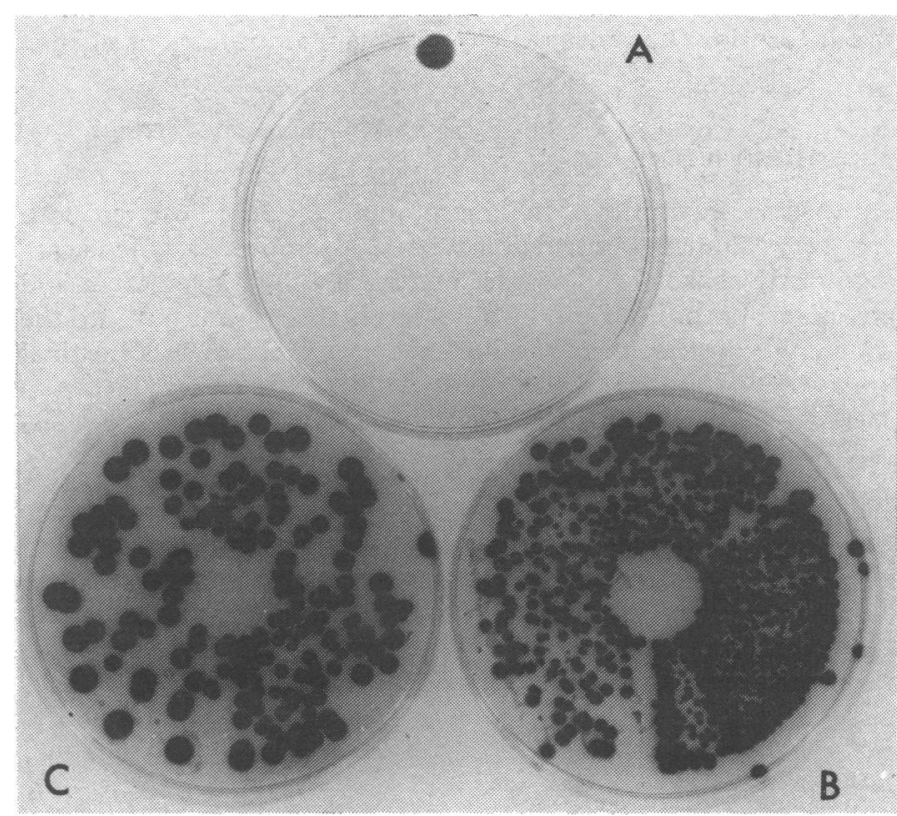

FIG. 1-Agar plates from air sampler. (A) Sample taken before the centrifuge was started. No tracer organism ( $S$. marcescens) detected. The only colonies are those of room contaminants. (B) Sample taken during centrifugation when three tubes leaked. Copious $S$. marcescens aerosol detected. (C) Sample taken five minutes after centrifugation at the opposite side of the room, taken five minutes after centrifugati
showing the spread of the aerosol. 
loaded; the second (B) was taken directly above the machine during the spinning, stopping, and opening of the centrifuge; and the third (C) was taken five minutes later, at the opposite side of the room. Twelve settle plates widely distributed around the room were not infected with $S$. marcescens, which gives some indication of the stability of the aerosol and of the dangerous futility of relying on settle plates for monitoring the risks of airborne infection.

\section{AUTOANALYZER SAMPLE STIRRER}

Our initial suspicions concerning the AutoAnalyzer stirrer were reinforced by the widespread blood splashes seen on a haematology laboratory model (see Fig. 2).

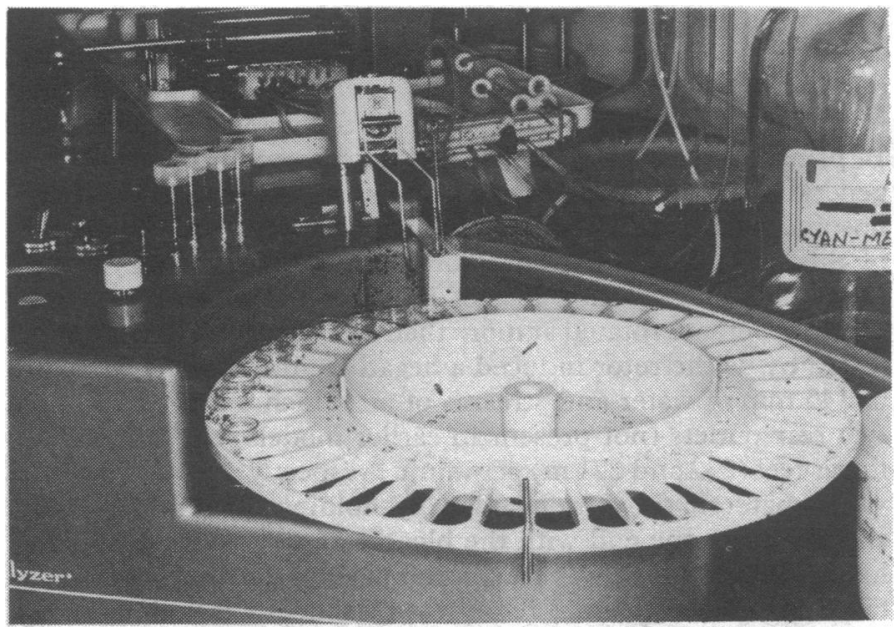

FIG. 2-AutoAnalyzer mixer in a clinical laboratory, showing blood splashes on and around the machine.

The air sampler tube was placed 1 in $(2.5 \mathrm{~cm})$ from the nearest stirrer paddle and at right angles to the plane of vibration. To our continuing surprise, and despite repeated testing, very few particles of $S$. marcescens were detected, either during stirring or when, in the course of the normal operation of the machine, the stirrer paddles were raised and lowered. Nevertheless, the state of the hospital machine would make us very reluctant to use it for blood samples which might contain infectious agents.

\section{MICROTONOMETER}

At least two examples of the microtonometer are in use but both are very similar in principle: paired samples of blood are vigorously shaken while a gas mixture is blown over them and any aerosol produced by the agitation is thus swept out into the room. We did not test an older machine which is in a hospital

TABLE II-Detected Aerosols Liberated by some Clinical Laboratory Apparatus

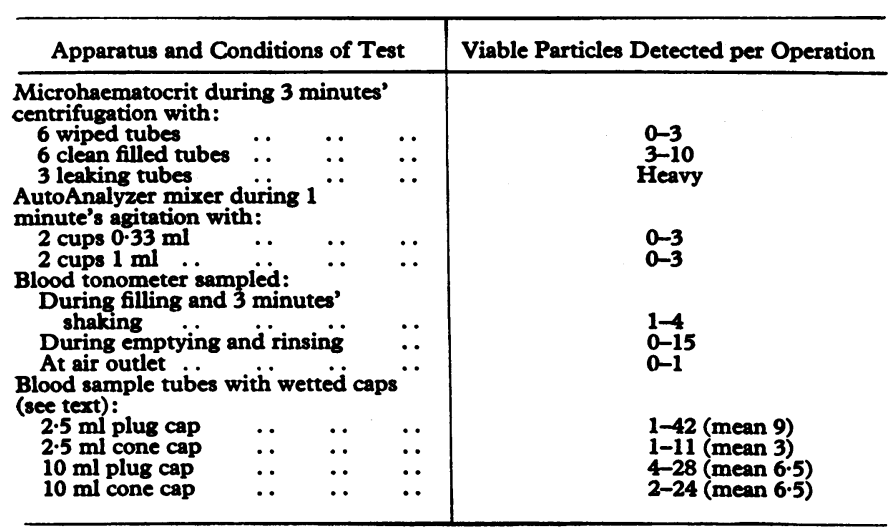

laboratory, but when we photographed it, it still bore traces of blood, despite the efforts of an assistant ("I didn't think you'd want to photograph it in the state it was in"). In repeated tests on a more recent model we did not detect more than a few viable particles of $S$. marcescens while introducing the sample or during the agitation phase (Table II). However, while the blood chambers were being emptied and rinsed with saline, up to 15 viable particles were detected when air was sampled at a point 21 in $(5.7 \mathrm{~cm})$ from the top of the blood chambers.

In this machine both the sample and chamber rinsing fluids are sucked by a small pump into a tubular trap, the air displaced by the pump emerging through an orifice on the front panel. The abundant splashing and frothing which occur in the trap prompted us to sample at the orifice. Very few particles were detected (Table II).

\section{BLOOD SAMPLE TUBES}

Opening bottles and tubes which contain infected fluids has long been known to be a potent source of aerosols (see, for example, Tomlinson, 1957), and during these experiments the opportunity was taken to examine some of the plastic specimen containers often used for blood samples. Containers of two types were tested, one with a simple plug-in plastic stopper, and a modified one with a cone screw cap which, the makers claim, "reduces infection hazards by improved leak proof characteristics, minimized aerosol effect, and significantly enhanced 'messproof' performance."

When tubes containing blood samples arrive at the laboratory the inner surfaces of the caps will be wet with blood from the shaking produced by transport. Accordingly, after the tubes had been filled they were inverted, and then, in front of the air sampler, the lids were removed and replaced several times, with the results shown in Table II. After the cone screw cap had been replaced more than twice, a bloody froth increasingly contaminated the outside of the tube and cap: the claim for enhanced messproof performance should perhaps be restricted to tubes opened no more than twice.

Tubes in which the stoppers or caps had not been wetted with blood were, as expected (Tomlinson, 1957), much less liable to create an aerosol. Unfortunately, in practice narrow metastable tubes, containing an anticoagulant which has to be well mixed with the blood, are unlikely ever to reach the clinical laboratory with dry lids. Thus aerosol and contagious hazards are present the moment the tubes are opened and before any analytical work is done on their contents.

\section{Discussion}

Our results provide further evidence of the hazards inherent in many routine laboratory techniques. Since many clinical laboratories can now expect several potentially lethal samples each week (see below) the apparent infrequency of laboratoryacquired disease among staff tends to encourage a complacency which is unjustifiable for two reasons: (i) time off work following hospital-acquired and laboratory-acquired infections is greater than that following other industrial injuries (Chatigny, 1961); and (2) the actual frequency of laboratory-acquired infection is probably higher than is generally assumed, partly because such infections are not notifiable, partly because many infections are never specifically diagnosed (being passed off as a severe cold or "influenza"), and partly because of the reluctance to acknowledge an infection as laboratory-acquired. For example, the director of a laboratory visited by Phillips (1961) first claimed that there had been only two cases of laboratory infection in his institute, but later remembered 22 more cases which included both himself and his wife.

Although statutory regulations govern the distribution of many drugs and poisons, the use of radioactive materials in laboratories, and the handling of many plant and some animal 
pathogens, there are, surprisingly, no legal requirements for handling materials potentially infectious for man; this despite the fact that these may present a more frequent and more alarming hazard.

Clinical laboratory staff may often include "school leavers" who, as juveniles, are legally barred from contact with radioactive materials. They are, nevertheless, often the people who first or most frequently handle samples sent to the laboratory. Almost the only official guidance for dealing with infective samples is contained in a report from the Public Health Laboratory Service which was recently revised and reissued by the Department of Health and Social Security (1970). This is solely concerned with specimens from tuberculous patients and has not legal authority; indeed, during 1970 less than one-third of the regional hospital laboratories handling tuberculous samples observed the recommended standard of protection for technical staff, and $13 \%$ of the laboratories did not even offer immunization against the disease (Guardian, 23 January 1971).

Many clinical laboratories already receive over 200 blood samples each working day, and as it has been found that, in Britain, about 1 in 200 blood donors is a symptomless carrier of infectious hepatitis (Hartney, 1970), several infected samples can be expected each week from apparently healthy persons or from patients with "non-hepatic" disorders. In addition, with the increasing incidence of septicaemia (Altemeier, 1967) a higher proportion of samples containing pathogenic bacteria can be expected. As greater use is made of international air travel, unexpected exotic diseases, imported unwittingly, will extend yet further the hazards to which laboratory staff are exposed.

The problem of infectious hepatitis among ciinical laboratory staff has led to the formulation of proposals by pathologists to minimize the risks, but those seen by us have concentrated on contagious risks, with but little appreciation either of the ease with which aerosols are generated or of their importance in laboratory-acquired infections. The assumption that aerosols of infectious hepatitis virus are innocuous, always dangerous, is now untenable since the report of Almeida et al. (1971), which strongly suggests that airborne transmission of infectious hepatitis can occur.

The only safe approach to handling samples which may contain unknown amounts of unknown pathogens is to regard them all as potentially lethal and, therefore, to carry out investigations on them with maximum safety precautions. In principle, this would require that an effective barrier be maintained be- tween specimens and staff at all times. This is unlikely to be accepted at present on the grounds of cost and inconvenience, although analogous precautions are used in various sectors of the electronics industry (Doxie and Ullom, 1967). Nevertheless, all clinical laboratory procedures of especial risk, such as opening specimen containers, centrifuging, and pipetting, should be isolated in properly maintained ventilated enclosures of suitable design (see, for example, Evans, Harris-Smith, and Stratton, 1972). Some of the dangers associated with bloodtaking (Table I) could be obviated by wider use of syringe-less methods, such as those using evacuated containers, although in their present form these are not entirely satisfactory. There can certainly be no justification for continuing to examine, in the open laboratory, specimens from known or suspected cases of infectious hepatitis and similar serious maladies. As nothing is more dangerous in microbiology than that which is thought to be safe, any pathological sample appearing at clinical laboratories should be regarded with the suspicion due to a Trojan horse: "Quidquid id est, timeo Danaos et dona ferentes" (Virgil).

We are grateful to Mr. J. Hunter for the photography.

\section{References}

Almeida, J. D., et al. (1971). Lancet, $2,849$.

Altemeier, W. A. (1967). Fournal of the American Medical Association, 202, 111.

Chatigny, M. A. (1961). In Advances in Applied Microbiology, vol. 3, p. 131. ed. W. W. Umbreit, New York, Academic Press.

Chatigny, M. A., and Clinger, D. I. (1969). In An Introduction to Experimental Aerobiology, ed. R. L. Dimmick and A. B. Akers, p. 195. New York, Wiley Interscience.

Darlow, H. M., (1969). In Methods in Microbiology, ed. J. R. Norris and D. W. Ribbons, vol. 1, p. 169, London, Academic Press.

Department of Health and Social Security (1970). Precautions Against Tuberculous Infection in the Diagnostic Laboratory. H.M.(70)60. London, H.M.S.O.

Doxie, F. T., and Ullom, K. J. (1967). Western Electric Engineer, 11, 24.

Evans, C. G. T., Harris-Smith, R., and Stratton, J. E. D. (1972). In Safety in Microbiology. Society for Applied Bacteriology, Technical Series 6. New York, Academic Press. In press.

Griffiths, P. D. (1971). Lancet, 2, 600.

Hartney, J. B. (1970). Fournal of the American Medical Association, 214, 461. Hawe, B. J., Goldsmith, H. J., and Jones, P. O. (1971). British Medical fournal, 1,540

Line, S. J. (1972). Fournal of Clinical Pathology, 25, 93.

McLellan, D. S., and Canning, D. M. (1971). Gazette of the Institute of Me tical Laboratory Technology, 15, 5.

Phillips, G. B. (1961). Microbiological Safety in U.S. and Foreign Laboratories. Technical Manuscript 35. Frederick, Maryland, U.S. Army Biological Pchnical Man

Sulkin, S. E. (1960). Unpublished observations quoted by Chatigny (1961).

Tomlinson, A. J. H. (1957). British Medical fournal, 2, 15.

\section{Metastases and the Normalization of Tumour Blood Vessels by ICRF 159: A New Type of Drug Action}

\section{A. W. LE SERVE, K. HELLMANN}

British Medical fournal, 1972, 1, 597-601

\section{Summary}

Profound modification of the structure and arrangement of the blood vessels has been shown in tumours after treatment with ICRF 159. $X$-ray angiography, carbon black (Pelikan ink) labelling, and intravital staining with lissamine green were used to demonstrate the changes. Alteration of the morphology of the blood

\footnotetext{
Department of Cancer Chemotherapy, Imperial Cancer Research
Fund, London WC2A 3PX

A. W. LE SERVE, B.SC., I.C.R.F. Bursar

K. HELLMAN, D.M., D.PHIL., Head
}

vessels at the edge of a tumour may affect the escape of malignant cells and the rate of blood flow (and thus the concentration of anticancer drugs) through the tumour.

\section{Introduction}

Treatment of the Lewis lung carcinoma (3LL) with ICRF 159 ( ( \pm$)-1,2$-bis(3, 5-dioxopiperazin-1-yl) propane) inhibits the pulmonary metastases resulting from bloodborne dissemination of 3LL cells (Hellmann and Burrage, 1969). The growth rate of the primary implant is, however, not significantly impeded by dosages required to produce this effect.

Histological examination of the possible mechanisms in- 